\title{
Some effects of reinforcer availability on the pigeon's responding in 24-hour sessions
}

\author{
GARY A. LUCAS \\ Indiana University, Bloomington, Indiana 47405
}

\begin{abstract}
Restrictions on food availability produced by schedules of reinforcement were examined in three homing pigeons continuously housed in operant chambers. Total daily access to food was free to vary and depended on the subject's contact with the schedule in effect. Experiment 1 varied reinforcer duration within a continuous reinforcement schedule in order to provide a description of the pigeon's feeding pattern under minimal constraints. In Experiments 2 and 3, access to food was contingent on responding in fixed-interval schedules, and limits on availability of food were varied by changing the duration of reinforcement (Experiment 2) or the frequency of reinforcement (Experiment 3). In all three experiments, a decline in the scheduled availability of food produced an increase in both the overall response rate and the local response rate. In addition, the distribution of responding across the day followed a diurnal rhythm typical of the pigeon's unconstrained pattern of food intake. These effects are consistent with previous studies showing an inverse relationship between instrumental response rate and reinforcer availability in the absence of fixed deprivation, and support the interpretation that this inverse relationship results from constraints imposed on preferred patterns of intake. The data on the local distribution of responses were consistent with an extension of the response-deprivation hy. pothesis (Timberlake \& Allison, 1974) to local response patterning.
\end{abstract}

A number of recent studies have shown that a substantial amount of instrumental behavior can be maintained by a contingency between the instrumental response and the reinforcer in the absence of a fixed deprivation regimen (for recent reviews, see Collier, Hirsch, \& Kanarek, 1977; Dunham, 1977; Hursh, 1980; Timberlake, 1980). Common to many of these studies is the hypothesis that restrictions on preferred amounts of one behavior can increase the occurrence of another behavior. For example, Timberlake and Allison (1974) have shown that the amount of an instrumental behavior will increase if a response contingency is arranged so that baseline levels of an instrumental response would result in less than the preferred (baseline) amount of a contingent behavior. This condition is called "response deprivation"' (see Allison \& Timberlake, 1974, 1975).

Hirsch and Collier (1974) also recognized that the reinforcement schedule produces certain restrictions on the pattern of reinforcer availability. For example, a schedule may restrict the frequency, duration, or amount of food available in a given time period. And these constraints may be more or less compatible with an organism's preferred pattern of ac-

The experiments reported here were part of a doctoral dissertation submitted to the University of Missouri at Kansas City. Special thanks are due to James Allison, James Deich, and Bill Timberlake for helpful suggestions on earlier versions of this manuscript. Requests for reprints should be sent to the author, Department of Psychology, Indiana University, Bloomington, Indiana $\mathbf{4 7 4 0 5}$. cess to that reinforcer. Hirsch and Collier proposed that "a major source of motivation in feeding behavior arises from constraints placed on the normal pattern of feeding" (1974, p. 239). From this perspective, Collier and his associates (Collier, Hirsch, \& Hamlin, 1972; Collier et al., 1977; Hirsch \& Collier, 1974; Kanarek, 1975) have used various schedules of food availability to model the environmental constraints of feeding behaviors found in different ecological niches.

The constraint argument essentially parallels the response-deprivation hypothesis when the "normal pattern" of intake is defined as the baseline pattern of the contingent behavior. Simply restated, the argument suggests that restricting a behavior below its baseline level of performance produces a change in motivation. ${ }^{1}$ In this way, the response-deprivation hypothesis predicts that a reduction in availability of a contingent behavior should increase the amount of an associated instrumental response. A number of studies using ratio schedules support the responsedeprivation prediction, reporting an inverse relation between instrumental response rate and reinforcer availability (see Allison, Miller, \& Wozny, 1979; Collier et al., 1977; Timberlake, 1977). Recently, Allison (1980) and Hursh (1978) have shown that the inverse relation between response rate and reinforcer availability does not depend on a ratio contingency between instrumental responding and the reinforcer.

The response-deprivation hypothesis can be extended to the patterning of behavior as well. Here re- 
sponse deprivation predicts that the baseline distribution of the contingent behavior should affect the distribution of instrumental activity in the contingency session (Allison \& Timberlake, 1975). For example, if most of the contingent behavior occurs in the last third of the session during the baseline condition, then, under a fixed rate of access to the contingent behavior, the largest discrepancy between the baseline amount and the scheduled amount would occur in the last third of the contingency session. The larger the difference between baseline and contingency periods, the greater the response-deprivation condition becomes and, therefore, the more instrumental activity to be expected. This extension of the responsedeprivation model to local response patterns will be termed the pattern-deprivation hypothesis. ${ }^{2}$ Support for this hypothesis rests largely on Allison and Timberlake's (1975) demonstration that the latency of an instrumental response in a contingency session depends on the latency of the contingent behavior during baseline.

The following study considered the role of the reinforcement schedule as a constraint. In particular, this design examined the effect of restricting availability of food on a pigeon's keypecking behavior. No requirement was placed on feeding aside from the limits on availability and no specific deprivation regimen was maintained. Availability of food was manipulated by varying either the duration of reinforcement (Experiments 1 and 2) or the frequency of reinforcement (Experiment 3). A fixed interval (FI) contingency was used in Experiments 2 and 3 to minimize the relationship between local rates of responding and the availability of food. These procedures therefore sought to extend Hursh's (1978) finding of an inverse relation between food availability and instrumental response rates under interval schedules.

In the present study, the reinforcement schedule was continuously available $24 \mathrm{~h}$ per day. A clear diurnal pattern for free-feeding behavior has been well defined for the pigeon (Zeigler, 1976; Zeigler, Green, \& Lehrer, 1971). This diurnal pattern provided a test of the pattern-deprivation prediction for the distribution of instrumental behavior. Given a fixed schedule restriction on food availability, the pattern-deprivation hypothesis predicts that the distribution of instrumental responding should approach the same diurnal pattern that feeding behavior shows under unconstrained conditions.

\section{GENERAL METHOD}

\section{Subjects}

Three homing pigeons, approximately 18 months old at the beginning of the study, served. All subjects had had prior experience with 24-h food-reinforcement schedules and had been maintained in individual operant chambers for 9 months. ${ }^{3}$ Each subject received 30 days of free access to mixed grain from food cups within each chamber prior to the present study. Ad-lib weights, based on means across the last 5 days in this period, were 610,328 , and $361 \mathrm{~g}$ for Subjects $\mathrm{H7401}, \mathrm{H} 7402$, and $\mathrm{H7403}$, respectively. These values served as reference points for $100 \%$ body weight.

\section{Apparatus}

A Lehigh Valley Model 1519 test chamber equipped with a Model 1348 two-key test panel and two locally constructed chambers of similar dimensions were used. Only the right response key was illuminated and operative. A minimum force of $.12 \mathrm{~N}$ was required to operate the response key.

The experimental chambers were located in a closed, lightshielded room. Ambient temperature was maintained between $20^{\circ}$ and $23^{\circ} \mathrm{C}$. In addition to the noise of the exhaust fan, a low level of white noise was continually presented through speakers in each chamber. Scheduling and data collection were programmed via conventional electromechanical relay equipment, counters, and cumulative recorders located in a separate room. Hourly response outputs were measured from the cumulative records.

A 12-h/12-h light-dark cycle was programmed by a single $7-\mathrm{W}$ night-light bulb centrally located on the ceiling of the chamber. A GE 1819 bulb operated at $28 \mathrm{~V}$ dc in series with a $150-\Omega$ resistor continuously illuminated the right response key with a dim orange color. A second 1819 bulb, located within the food hopper, was illuminated when the hopper was raised. This arrangement provided the pigeon with visual access to the key and food hopper during both light and dark periods of the day.

Water and grit were available from small cups located to the left of the food hopper. The pigeon's food was a mixture of chopped corn and other small grains of relatively uniform size averaging $.02 \mathrm{~g}$ per piece.

\section{Procedure}

The subjects remained in their experimental chambers continuously, except for approximately $5 \mathrm{~min}$ each day, during which the subjects were removed for weighing, cleaning the chamber, and replenishing food and water supplies. Cleaning occurred approximately $30 \mathrm{~min}$ prior to light onset.

To provide a measure of the time a subject spent in keypecking behavior, each keypeck was programmed to start, or restart, a 15-sec clock. Each bout of keypecking started the clock, which ran until $15 \mathrm{sec}$ had elapsed without a response. Timing was suspended during reinforcement, but the clock restarted if the subject keypecked during food delivery. A running timemeter recorded the cumulative time each day that the 15 -sec clock was active. This measure of "cumulative time responding" provided the time base used to compute local rates of responding and local reinforcement frequencies.

Subjects gained all daily access to food by keypecking under various schedules of reinforcement. The amount of food obtained per day varied freely according to the subject's performance. Food intake was measured by the difference in weight between the original grain supply each day and the weight remaining (plus any spillage) on the following day. The reinforcement schedule operated during both light and dark periods of the day. To simplify time references, daily session time was defined with respect to the subject's light-dark cycle. The midpoint of the dark period was designated as the change of day. In this time reference, the houselight went on at $0600 \mathrm{~h}$ and off at $1800 \mathrm{~h}$.

The same three subjects served in each of the following studies. In order of running, the study reported as Experiment 2 actually preceded the study in Experiment 1. The order of discussion has been reversed as an aid to presentation.

\section{EXPERIMENT 1}

Zeigler et al. (1971) have provided a detailed description of the pigeon's free-feeding behavior. Ex- 
periment 1 attempted to determine whether similar behavior patterns would develop in the pigeon living and feeding in an operant chamber. Previous studies (Duncan, Horne, Hughes, \& Wood-Gush, 1970; McFarland, 1967) have suggested that the operant situation can provide a good assessment of free-feeding performance in avians when minimal response requirements are used. To this end, the following study used a continuous reinforcement schedule (CRF) in which each keypeck produced food delivery.

\section{Method}

Nominal hopper durations were selected from the doubling series $1.5,3,6,12$, and $24 \mathrm{sec}$. In order to minimize error in the usable duration of the hopper, a constant $.4 \mathrm{sec}$ time was added to each value in the above series. The .4-sec allowance was judged the minimum transit time from the response key to the food hopper based on pilot observations of highly motivated pigeons trained in the same chambers. The actual duration of each presentation was therefore $.4 \mathrm{sec}$ longer than the nominal value. Reinforcer durations were presented in ascending order, with each duration in effect for 7 days.

Keypecks during the reinforcer had no scheduled effect, but did restart the 15-sec clock recording time spent responding. Event records from individual subjects for keypecking were analyzed to determine the extent of local periods of feeding activity. A bout of responding was defined as a period of pecking separated from other response periods by a minimum of 2 min with no responding (cf. Zeigler et al., 1971).

\section{Results and Discussion}

Although the reinforcement schedule in each condition was operative $24 \mathrm{~h}$ a day, the pigeon's feeding activity was not equally distributed across the day. Instead, the daily response pattern followed a marked diurnal rhythm, with more than $98 \%$ of all responses occurring during the lighted period of the light-dark cycle $(0600$ to $1800 \mathrm{~h})$. Figure 1 presents the temporal
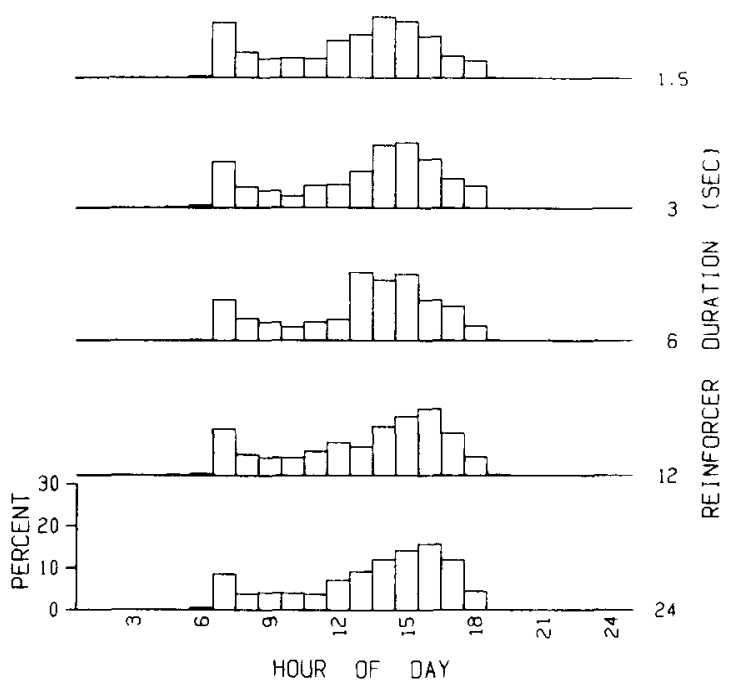

Figure 1. The mean percentage of daily reinforcers obtained per hour across CRF schedules in Experiment 1. Light onset occurred after Hour 6 (0600), light offset after Hour 18 (1800). distribution of reinforcers across hours of the day. Data are mean percentages of reinforcers for the last 5 days in the condition averaged across subjects and are representative of individual response patterns as well.

The distribution of responding within the light period was characterized by a bimodal pattern of activity with a primary peak of responding in the "afternoon" period of the day between 1400 and $1600 \mathrm{~h}$. A secondary peak of responding occurred between 0600 and $0800 \mathrm{~h}$, following light onset. This "morning" response peak was generally smaller than the afternoon peak and was occasionally absent from individual daily records. Response rate during the "midday" period, 1000 to $1300 \mathrm{~h}$, was characteristically low. Responding during the dark period of the light-dark cycle was limited to an occasional feeding bout during those early morning hours just preceding light onset. This pattern of responding is consistent with the distribution of feeding activity reported by Zeigler et al. (1971) as being typical of the pigeon's daily feeding pattern. Little variation in this pattern was evident across changes in reinforcer duration.

Summary measures for daily feeding activity are presented in Table 1. Data are means across the last 5 days in each condition, except as noted. All three subjects readily adjusted their feeding activity to changes in reinforcer duration. As duration increased from a nominal value of $1.5 \mathrm{sec}$ per reinforcer to $24 \mathrm{sec}$ per reinforcer, the total number of reinforcers obtained per day and measures of cumulative time spent keypecking (based on the 15-sec time envelope following each keypeck) both decreased. Despite the change in reinforcer duration, the mean number of distinct bouts of feeding activity remained relatively constant across conditions. Similarly, food intake was relatively constant, although intake was clearly depressed at the 1.5-sec reinforcer duration.

Also presented in Table 1 are measures of the mean daily access time to food (number of reinforcers times nominal duration) and rate of food intake (grams eaten per minute of access to food). These measures suggest that much of the pigeon's ability to compensate for shorter reinforcer durations results from an increase in feeding rate. The interested reader may note that rate of food intake in grams per minute provides a good estimate of foodpeck rates in pecks per second with the grain mixture used in the present study. ${ }^{4}$ The measures of "access time" and "rate of feeding" obtained with the present operant procedure compare with a mean daily access time of $51.9 \mathrm{~min}$ and a feeding rate of $.58 \mathrm{~g} / \mathrm{min}$ based on photocell-controlled feedometer measures of feeding in adult White Carneaux pigeons (Zeigler et al., 1971).

The final three measures in Table 1 describe the within-bout pattern of feeding activity. At shorter 
Table 1

Summary Measures for Experiment 1

\begin{tabular}{|c|c|c|c|c|c|c|c|c|c|c|c|c|c|}
\hline \multicolumn{14}{|c|}{ Measure } \\
\hline \multirow{2}{*}{$\begin{array}{c}\text { Sec } \\
1 \\
\end{array}$} & \multicolumn{2}{|c|}{2 Reinf } & \multicolumn{2}{|c|}{$3 \mathrm{Min}-\mathrm{R}$} & \multicolumn{2}{|c|}{4 Bouts } & \multicolumn{2}{|c|}{$5 \mathrm{Gm} \mathrm{Fd}$} & \multirow{2}{*}{$\begin{array}{c}\text { Min-F } \\
6 \\
\end{array}$} & \multirow{2}{*}{$\begin{array}{c}\mathrm{Gm} / \mathrm{M} \\
7 \\
\end{array}$} & \multirow{2}{*}{$\begin{array}{c}\mathrm{Rf} / \mathrm{B} \\
8 \\
\end{array}$} & \multirow{2}{*}{$\begin{array}{c}\mathrm{Sec} / \mathrm{B} \\
9 \\
\end{array}$} & \multirow{2}{*}{$\begin{array}{c}\text { IRfT } \\
10 \\
\end{array}$} \\
\hline & Mean & SE & Mean & SE & Mean & SE & Mean & SE & & & & & \\
\hline \multicolumn{14}{|c|}{ Subject H7401 } \\
\hline $\begin{array}{r}1.5 \\
3.0 \\
6.0 \\
12.0 \\
24.0\end{array}$ & $\begin{array}{l}782.6 \\
510.4 \\
389.2 \\
297.4 \\
187.8\end{array}$ & $\begin{array}{l}31.6 \\
36.1 \\
11.7 \\
24.6 \\
10.5\end{array}$ & $\begin{array}{l}63.5 \\
56.0 \\
58.0 \\
60.9 \\
47.3\end{array}$ & $\begin{array}{l}3.0 \\
6.5 \\
1.5 \\
4.7 \\
3.3\end{array}$ & $\begin{array}{l}39.3 \\
44.8 \\
46.6 \\
41.2 \\
38.4\end{array}$ & $\begin{array}{l}1.7 \\
2.9 \\
2.5 \\
3.9 \\
3.9\end{array}$ & $\begin{array}{l}20.8 \\
22.8 \\
24.7 \\
25.6 \\
24.2\end{array}$ & $\begin{array}{r}1.3 \\
1.1 \\
1.1 \\
.8 \\
1.2\end{array}$ & $\begin{array}{l}19.6 \\
25.5 \\
38.9 \\
59.5 \\
75.1\end{array}$ & $\begin{array}{r}1.06 \\
.89 \\
.63 \\
.43 \\
.32\end{array}$ & $\begin{array}{r}19.91 \\
11.39 \\
8.35 \\
7.22 \\
4.89\end{array}$ & $\begin{array}{r}29.9 \\
34.2 \\
50.1 \\
86.6 \\
117.4\end{array}$ & $\begin{array}{r}4.12 \\
5.27 \\
7.15 \\
10.20 \\
12.04\end{array}$ \\
\hline \multicolumn{14}{|c|}{ Subject H7402 } \\
\hline $\begin{array}{r}1.5 \\
3.0 \\
6.0 \\
12.0 \\
24.0\end{array}$ & $\begin{array}{r}303.4 \\
229.8 \\
171.2 \\
79.2 \\
49.0\end{array}$ & $\begin{array}{r}20.9 \\
11.5 \\
11.7 \\
1.7 \\
1.7\end{array}$ & $\begin{array}{l}29.9 \\
28.4 \\
26.9 \\
16.1 \\
12.5\end{array}$ & $\begin{array}{r}1.2 \\
.9 \\
1.5 \\
.4 \\
.8\end{array}$ & $\begin{array}{l}31.6 \\
31.6 \\
22.2 \\
23.4 \\
23.2\end{array}$ & $\begin{array}{r}2.1 \\
1.9 \\
2.1 \\
.7 \\
.6\end{array}$ & $\begin{array}{l}11.1^{*} \\
13.0^{*} \\
13.2 \\
12.8 \\
12.1\end{array}$ & $\begin{array}{l}.6 \\
.7 \\
.9\end{array}$ & $\begin{array}{r}7.6 \\
11.5 \\
17.1 \\
15.8 \\
19.6\end{array}$ & $\begin{array}{r}1.46 \\
1.13 \\
.77 \\
.81 \\
.62\end{array}$ & $\begin{array}{l}9.60 \\
7.27 \\
7.71 \\
3.38 \\
2.11\end{array}$ & $\begin{array}{l}14.4 \\
21.8 \\
46.3 \\
40.6 \\
50.6\end{array}$ & $\begin{array}{l}4.35 \\
5.35 \\
7.48 \\
7.77 \\
8.20\end{array}$ \\
\hline \multicolumn{14}{|c|}{ Subject $\mathrm{H} 7403$} \\
\hline $\begin{array}{r}1.5 \\
3.0 \\
6.0 \\
12.0 \\
24.0\end{array}$ & $\begin{array}{r}747.6 \\
445.6 \\
248.2 \\
150.8 \\
93.6\end{array}$ & $\begin{array}{r}42.3 \\
7.6 \\
14.0 \\
8.4 \\
6.7\end{array}$ & $\begin{array}{l}57.7 \\
50.1 \\
36.7 \\
33.7 \\
24.9\end{array}$ & $\begin{array}{l}3.1 \\
3.2 \\
2.2 \\
2.1 \\
1.7\end{array}$ & $\begin{array}{l}47.2 \\
52.6 \\
44.4 \\
49.8 \\
48.0\end{array}$ & $\begin{array}{r}.9 \\
4.9 \\
1.4 \\
3.4 \\
3.9\end{array}$ & $\begin{array}{l}18.0 * \\
19.9 \\
19.9 \\
21.5 \\
20.0\end{array}$ & $\begin{array}{r}1.2 \\
.9 \\
1.1 \\
1.2\end{array}$ & $\begin{array}{l}18.7 \\
22.3 \\
24.8 \\
30.2 \\
37.4\end{array}$ & $\begin{array}{l}.96 \\
.89 \\
.80 \\
.71 \\
.53\end{array}$ & $\begin{array}{r}15.84 \\
8.47 \\
5.59 \\
3.03 \\
1.95\end{array}$ & $\begin{array}{l}23.8 \\
25.4 \\
33.5 \\
36.4 \\
46.8\end{array}$ & $\begin{array}{l}3.68 \\
4.98 \\
6.19 \\
8.45 \\
8.26\end{array}$ \\
\hline
\end{tabular}

Note-All data are means based on the last 5 days in each condition. Measures: (1) reinforcer duration (in seconds), (2) reinforcers, (3) time responding (in minutes), (4) feeding bouts, (5) food intake (in grams), (6) access time to food (in minutes), (7) rate of food intake (in grams per minute), (8) reinforcers per bout, (9) food access per bout (in seconds), and (10) local interreinforcer time (in seconds). $\quad$ *Food intake measures in these conditions are incomplete; data are means based on the available data.

reinforcer durations, the pigeon increased the number of reinforcers obtained per bout, but failed to obtain total durations of access to food comparable to those found at longer reinforcer durations. The increased frequency of reinforcers per bout was accompanied by a decrease in time between reinforcer presentations. In contrast, at longer durations, fewer reinforcers were obtained and the interval between them increased. The local interreinforcement time shown in Table 1 was based on the measure of time spent responding corrected for time accumulated between bouts. Since the cumulative time measure was based on a 15-sec time envelope following each response, this measure was not sensitive to changes in interreinforcer times exceeding $15 \mathrm{sec}$, and therefore underestimates the mean within-bout interreinforcement time. Instead, changes in this measure represent changes in the frequency of initiating a second reinforcer within $15 \mathrm{sec}$ from the end of a previous reinforcement period. Some implications of this change in local feeding rate will be discussed later.

The overall duration of access to food accumulated by the pigeon at the longer reinforcer durations requires some additional comment. In particular, it is clear that a substantial increase in access time occurred at the longer reinforcer durations with little change in amount eaten. A photocell located within the food hopper for Subject $\mathrm{H} 7403$ indicated that across longer durations this subject responded (head into hopper) on more than $97 \%$ of all hopper presentations. However, further observation under these conditions indicated that although the pigeon consistently responded to the hopper, it spent only part of this time actually consuming food. At longer reinforcer durations, increasing time was spent inspecting the food, looking but not pecking, and in sorting behavior, a sideways displacement with the beak that serves to expose underlying material to view. The increase in sorting activity was accompanied by a tendency to select differentially some types of grain from the mixture of grains presented. This tendency was not evident at rates of food intake above $.60 \mathrm{~g} /$ min (see Table 1), a feeding rate comparable to about 36 foodpecks/min. For this reason, access times in Table 1 accompanied by lower rates of intake than $.60 \mathrm{~g} / \mathrm{min}$ may be considered inflated. ${ }^{5} \mathrm{On}$ this basis, restricting local access times to less than $36 \mathrm{sec} / \mathrm{bout}$ may be considered a conservative estimate for the minimum constraint necessary to interfere with the pigeon's preferred feeding pattern.

Based on feeding patterns under the 6-sec reinforcer duration, the mean interval between feeding bouts during the lighted part of the daily cycle was about $14 \mathrm{~min}$, with fewer than $3 \%$ of the total interbout times exceeding $50 \mathrm{~min}$. However, this mean interval is somewhat misleading, since feeding bouts 
were more frequent during the high-activity feeding periods of the afternoon than during other periods of the day. The interbout interval during these more active periods was commonly 6 to $8 \mathrm{~min}$, while interbout times during the low activity midday period frequently exceeded $30 \mathrm{~min}$. A similar change in bout frequency has been reported by Zeigler et al. (1971), who also report an increase in bout duration during more active feeding periods.

\section{EXPERIMENT 2}

Rather than eating a few distinct meals per day, the pigeon's free-feeding activity is characterized by frequent small bouts of eating primarily limited to the daylight hours (Zeigler et al., 1971; and Experiment 1). The frequency and duration of feeding bouts vary across the daylight hours to produce a bimodal pattern, with the bulk of the pigeon's intake occurring in the afternoon period. Detailed descriptions of the pigeon's feeding activity obtained in the laboratory (Zeigler, 1976; Zeigler et al., 1971) are supported by field observations for the pigeon and related species (e.g., Murton, 1965; Schmid, 1965) and laboratory studies of other avians (Duncan et al., 1970; VanHemel \& Meyer, 1969), showing a diurnal pattern of frequent small feeding bouts. Similar patterns of responding emerged in the pigeon's keypecking activity in Experiment 1 when food was obtained under a simple CRF reinforcement schedule.

The following study extended the operant contingency to a moderate fixed-interval (FI) schedule. The FI schedule differed from the CRF condition in that it imposed a limit on the maximum local frequency of access to food. Assuming that the duration of the reinforcement period was relatively long, such a schedule might place little restriction on the pigeon's ability to feed in frequent small bouts. However, at shorter reinforcer durations, the FI would prevent the pigeon from producing additional periods of access to food within a few seconds of the previous reinforcement period, as found at shorter reinforcer durations in Experiment 1. Viewed either in responsedeprivation terms (Timberlake \& Allison, 1974) or as a constraint on the usual feeding pattern (Hirsch \& Collier, 1974), the restrictions imposed by the schedule were expected to increase the amount of associated food-directed behaviors. Since longer and more frequent feeding bouts occurred in the early morning and afternoon periods, shorter reinforcer durations would particularly conflict with the pigeon's typical feeding pattern during these periods. Thus, the largest amount of keypecking was expected during these hours of the day.

\section{Method}

The same three pigeons used in Experiment 1 served as subjects. The subjects were adjusted to an FI 1-min schedule with a 6-sec duration of access to food for 1 week prior to the present study. Each subject was then exposed to a series of reinforcer durations varying in an ascending and then a descending order, as shown in Table 2. As in Experiment 1, a constant .4-sec time allowance was added to each nominal duration. In all conditions, the FI 1-min was timed from the offset of the previous reinforcement period. Except for the 1.5-sec duration, which ran for 12 days, each reinforcer duration was in effect for 10 consecutive days. All other details of the apparatus and procedure were identical to those used in Experiment 1.

\section{Results and Discussion}

The major results of Experiment 2 are summarized in Figure 2. Additional measures are provided in Table 2 . All data are means across the last 5 days in each condition, except as noted. For each subject, the total number of keypecks made per day (the overall response rate) and the local rate of pecking (calculated with the cumulative time spent responding as the time base) were both an inverse function of the duration of access to food per reinforcer. The number of responses emitted per reinforcer was also an inverse function of reinforcer duration, as was the number of reinforcers produced per day. While the number of reinforcers obtained per day increased as reinforcer duration was reduced, the local rate of reinforcer delivery (based on the same time base as local response rate) decreased at shorter reinforcer durations. These effects were consistent across subjects for both the ascending and descending series.

Since the cumulative time measure was based on a 15-sec time period following each keypeck, the local rate measure indicates a change in interresponse times shorter than $15 \mathrm{sec}$. Similarly, the change in the number of responses per reinforcer represents an increase in the number of responses initiated within $1 \mathrm{~min}$ of a previous reinforcer under the FI 1 -min schedule. These measures illustrate that the recorded change in local response rate was not simply an artifact of the subjects' production of more reinforcers at shorter hopper durations. The number of responses changed more rapidly than did the number of reinforcers. In addition, the increase in local response rate occurred despite a substantial increase in the overall duration of time spent responding per day (see Table 2), the time base for calculating local rates. The estimates of local response rate determined with this time base are necessarily biased by the method of determining the measure of time spent responding. In particular, the rate measure was insensitive to local response rates below $4 / \mathrm{min}$. However, the direction of change in local rate was consistent with estimates of local rate based on the examination of cumulative records, based on the number of responses per reinforcer, and based on measures of peak afternoon response rates. Thus, while the absolute response rate may differ, depending on the time base used, the direction of change was consistent across measures. 

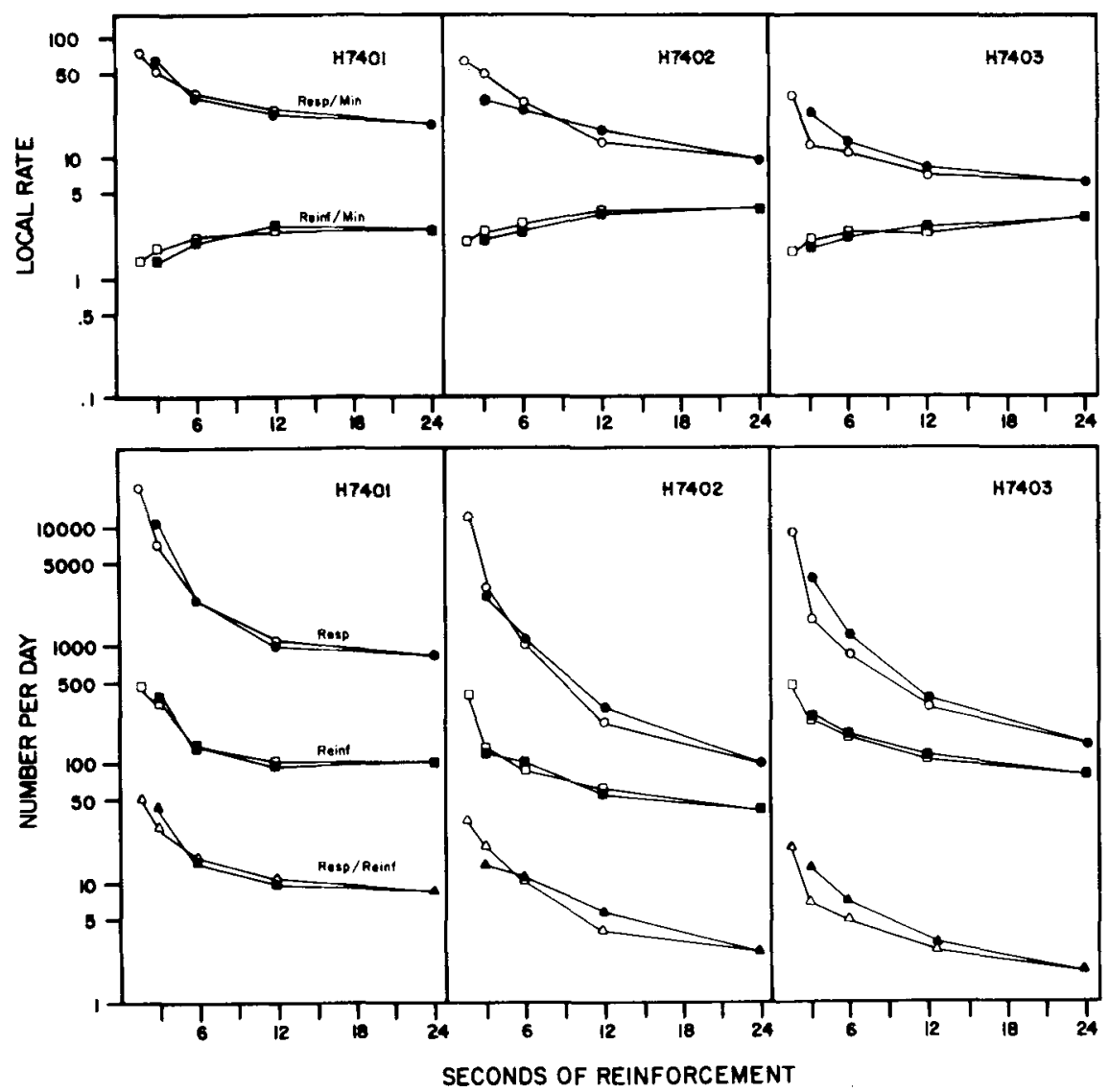

Figure 2. Top, local response rate (circles), local rate of reinforcement (squares). Bottom, total responses per day (circles), total reinforcers per day (squares), and the mean number of responses per reinforcer (triangles). Data are from Experiment 2 and are plotted as a function of the scheduled reinforcer duration. Solid figures are from the ascending series, open figures are from the descending series.

In addition to the measure of time spent responding, Table 2 presents the mean daily access time to food (number of reinforcers times nominal duration) and the mean percentage of body weight maintained across conditions. The reduction in reinforcer duration clearly resulted in a net decrease in the obtained duration of access to food per day. Compared with the data from Experiment 1 (see Table 1), the duration of access obtained under the FI 1-min schedule was systematically lower. The percentage of body weight maintained across conditions was lower at shorter reinforcer durations, especially for $\mathrm{H} 7401$, but was not consistently predictive of the level of responding. Subject $\mathrm{H} 7403$ maintained a body weight within $2.4 \%(9 \mathrm{~g})$ of its ad-lib weight across all conditions. Since daily access time to food decreased at shorter durations, the small change in body weight suggests that the pigeon was able to compensate substantially for the reduced access time. Presumably this was accomplished by increasing the rate of eat- ing, as in Experiment 1. Unfortunately, measures of food intake were not obtained to confirm this hypothesis.

Figure 3 presents the distribution of keypecking across hours of the day. Data are mean percentages averaged across subjects and based on performance during the last 5 days in each condition. The conditions shown in Figure 3 were all based on performance across the descending series of reinforcer durations. As in Experiment 1, responding followed a bimodal distribution with a primary peak of activity during the afternoon portion of the day. Compared with the CRF distributions (see Figure 1), the afternoon peak of activity appeared somewhat later. In addition, the proportion of total responding occurring in the early morning peak was considerably smaller in Experiment 2, with a greater proportion of responding occurring, instead, during the afternoon. Using hourly percentage distributions from the CRF data (averaged across all five conditions) as expected val- 
Table 2

Summary Measures for Experiment 2

\begin{tabular}{|c|c|c|c|c|c|}
\hline \multirow{2}{*}{$\begin{array}{l}\text { Reinforcer } \\
\text { Duration* }\end{array}$} & \multicolumn{2}{|c|}{$\begin{array}{c}\text { Access Time to } \\
\text { Food (in Minutes) }\end{array}$} & \multicolumn{2}{|c|}{$\begin{array}{l}\text { Time Responding } \\
\text { (in Minutes) }\end{array}$} & \multirow{2}{*}{$\begin{array}{c}\text { Percentag } \\
\text { Weight }\end{array}$} \\
\hline & Mean & $\mathrm{SE}$ & Mean & $\mathrm{SE}$ & \\
\hline \multicolumn{6}{|c|}{ Subject H7401 } \\
\hline 3.0 & 13.7 & 6 & 176.8 & 14.8 & 99.3 \\
\hline 6.0 & 15.3 & .6 & 71.8 & 4.4 & 99.2 \\
\hline 12.0 & 20.5 & .9 & 39.3 & 3.6 & 97.7 \\
\hline 24.0 & 40.8 & 1.2 & 42.8 & 3.3 & 97.8 \\
\hline 12.0 & 21.1 & 1.8 & 41.5 & 4.8 & 96.9 \\
\hline 6.0 & 15.3 & .7 & 73.7 & 3.7 & 95.9 \\
\hline 3.0 & 11.5 & .2 & 127.4 & 4.4 & 92.8 \\
\hline 1.5 & 11.2 & .3 & 282.6 & 10.1 & 85.8 \\
\hline \multicolumn{6}{|c|}{ Subject $\mathrm{H} 7402$} \\
\hline 3.0 & 7.4 & .5 & 70.3 & 8.5 & 99.6 \\
\hline 6.0 & 9.7 & .2 & 38.2 & 1.9 & 97.7 \\
\hline 12.0 & 11.6 & .7 & 16.1 & 1.1 & 97.3 \\
\hline 24.0 & 16.4 & 1.0 & 11.4 & .8 & 97.3 \\
\hline 12.0 & 11.7 & .6 & 16.3 & .7 & 97.0 \\
\hline 6.0 & 9.0 & .4 & 32.1 & 1.7 & 97.0 \\
\hline 3.0 & 7.3 & .2 & 58.4 & 2.2 & 95.7 \\
\hline 1.5 & 9.6 & .3 & 184.1 & 7.5 & 96.1 \\
\hline \multicolumn{6}{|c|}{ Subject $\mathrm{H} 7403$} \\
\hline 3.0 & 12.8 & .4 & 130.9 & 7.0 & 99.0 \\
\hline 6.0 & 17.8 & 1.0 & 76.2 & 6.4 & 98.4 \\
\hline 12.0 & 22.4 & .6 & 40.8 & 1.8 & 100.7 \\
\hline 24.0 & 32.6 & 1.9 & 24.7 & 1.6 & 100.6 \\
\hline 12.0 & 21.6 & 1.2 & 41.5 & 3.4 & 101.7 \\
\hline 6.0 & 16.6 & 1.2 & 65.1 & 4.2 & 101.6 \\
\hline 3.0 & 12.6 & .4 & 119.1 & 3.6 & 101.0 \\
\hline 1.5 & 10.9 & .6 & 245.1 & 5.5 & 97.6 \\
\hline
\end{tabular}

Note-All data are means based on the last 5 days in each condition except percentage weight data, which are 3-day means.

*In seconds.

ues, the daylight distributions shown in Figure 3 were found to be significantly different from the CRF distribution at the 12-, 6-, and 3-sec reinforcer durations $\left[\chi^{2} s(11)=49.0,61.8\right.$, and 60.0 , respectively, all ps $<$ $.01]$, but not at the $24-\mathrm{sec}$ or the $1.5-\mathrm{sec}$ durations $\left[\chi^{2} s(11)=5.3\right.$ and 15.5 , ps $\left.>.15\right]$.

\section{EXPERIMENT 3}

Experiment 2 demonstrated an inverse relationship between the response rate and reinforcer availability when food availability was constrained by limiting reinforcer duration. Similar effects occurred in Experiment 1 under CRF schedules. However, in both the preceding studies, the higher response rate obtained at shorter reinforcer durations was accompanied by an increase in the number of reinforcers obtained per day. This increase in number of reinforcers was not sufficient to compensate for the reduction in daily duration of access to food. However, the higher frequency of reinforcement might have contributed to changes in response rate obtained in the preceding studies if frequency of reinforcement was the primary determinant of the "strength" of reinforcement. Experiment 3 therefore examined the effects of constraints on the availability of food imposed by varying the length of the fixed interval between reinforcers. This procedure specifically controlled the maximum frequency of reinforcement available, while the duration of access to food per reinforcer remained constant. As in the preceding studies, the overall level of access to food per day depended on the subject's contact with the reinforcement schedule.

\section{Method}

The same three pigeons used in Experiments 1 and 2 served as subjects. Reinforcer duration in all the following conditions was fixed at $6 \mathrm{sec}$ (plus the .4-sec transit time). The maximum available frequency of reinforcement was varied across conditions by increasing the length of the fixed-interval schedule in the following series: FI .25, .5, 1, 2, 4, and $8 \mathrm{~min}$. Note that increasing the length of an FI schedule limited the maximum local rate of reinforcer availability, but did not necessarily ensure that fewer total reinforcement periods would be obtained per day. Each subject remained under the .25-, .5-, and $1-$ min FI values for 10 days before advancing to the next condition. The 2-, 4-, and 8-min FI values each remained in effect for 14 days. The remaining details of the apparatus and procedure were identical to those described earlier.

\section{Results and Discussion}

The results are summarized in Figure 4 and Table 3. All data are means across the last 5 days in each condition except as noted. The data in Figure 4 are plotted across the maximum local frequency of reinforcement allowed by the FI schedule. The order of running was actually from right to left.

Replicating Experiment 2, the total number of responses emitted per day (the overall response rate), the local rate of responding, and the total number of responses produced per reinforcer, all followed an in-

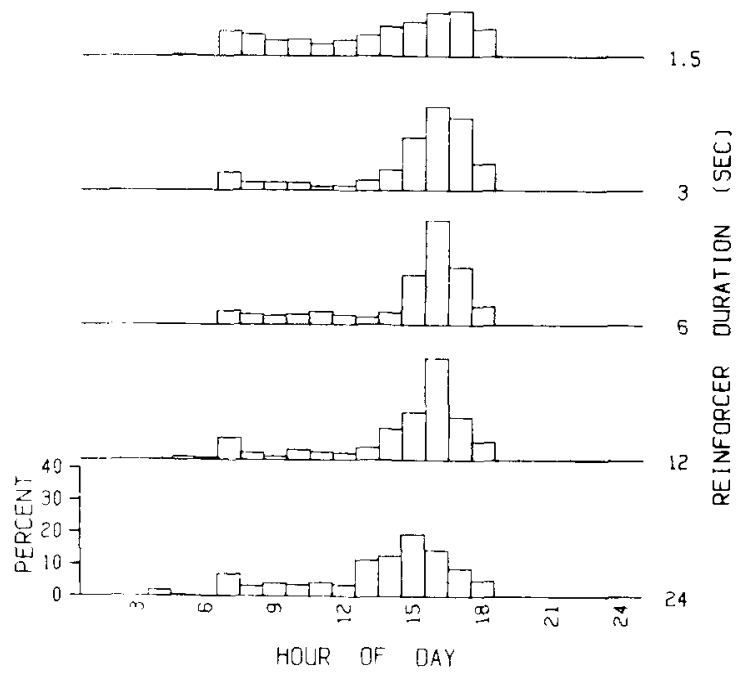

Figure 3. The mean percentage of dally responses distributed across hours of the day in Experiment 2. Light onset occurred after Hour $6(0600)$, light offset after Hour 18 (1800). 

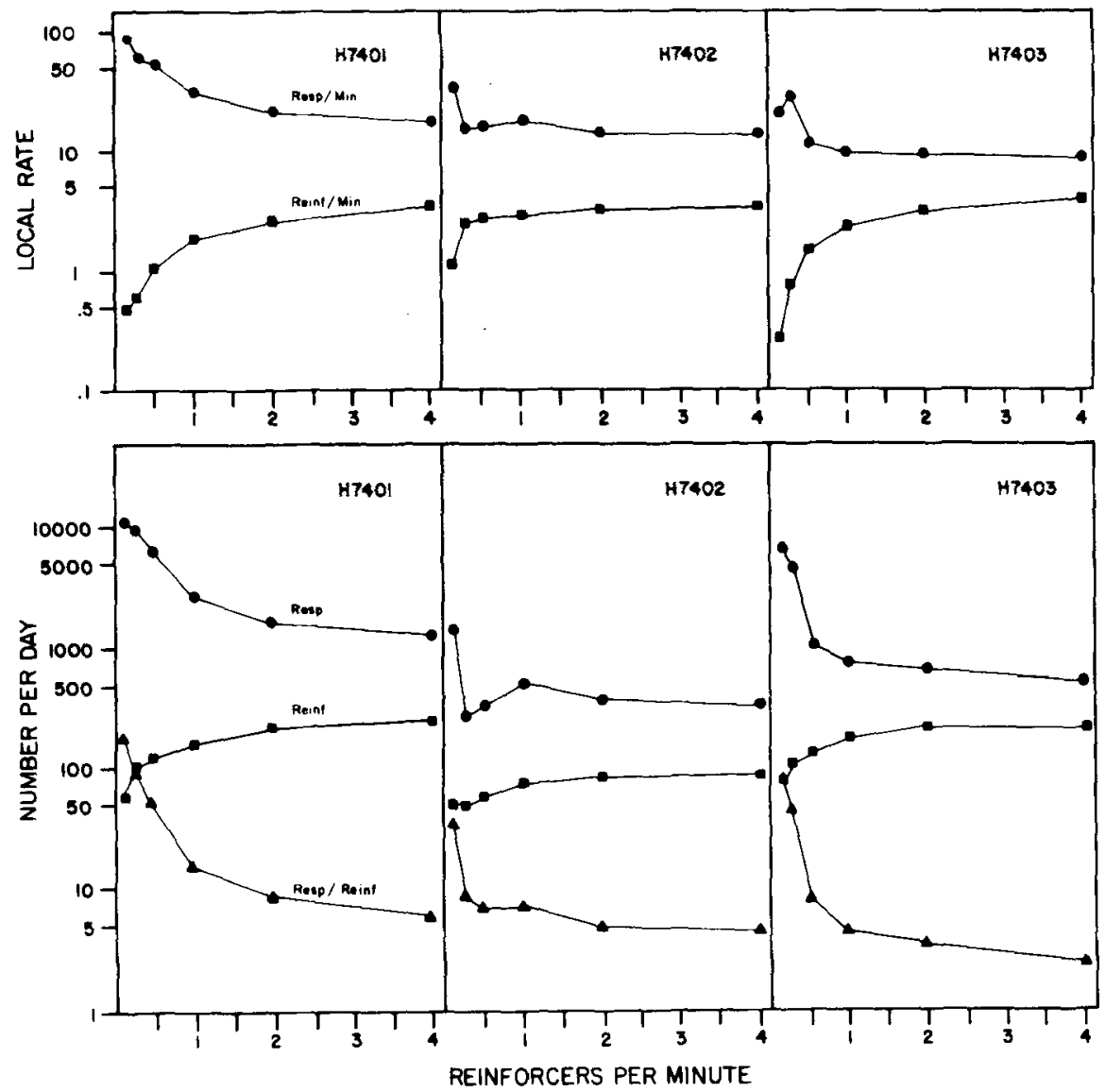

Figure 4. Top, local response rate (circles), local rate of reinforcement (squares). Bottom, total responses per day (circles), total reinforcers per day (squares), and the mean number of responses per reinforcer (triangles). Data are from Experiment 3 plotted as a function of the scheduled reinforcement frequency.

verse function of the availability of food. In contrast to the preceding studies, the overall number of reinforcers obtained per day and the local rate of reinforcement both decreased as the maximum frequency of reinforcement decreased. The higher response rate, therefore, cannot be attributed to an increase in either the overall rate of reinforcement or the local rate of reinforcement.

Included in Table 3 are measures of total access time to food (nominal duration times number of reinforcers) across each schedule condition. As in Experiment 2, the obtained duration of access to food decreased across schedule constraints to values well below those obtained under the CRF conditions (see Table 1). The total amount of food consumed per day and the mean weight of food obtained per 6-sec reinforcer are shown in Figure 5 across the scheduled frequency of reinforcement. As the maximum available frequency of reinforcers decreased, the pigeon increased its rate of feeding during the 6-sec reinforcer. However, this increase was not sufficient to compensate for the reduced access to food at reinforcement frequencies below $1 / \mathrm{min}$, as shown by the sharp decrease in total food obtained. Despite the decrease, changes in body weight (see Table 3 ) were relatively small and markedly lagged behind the changes in food intake. Also apparent from these measures is the rather extreme degree of deprivation necessary to reduce the pigeon to an $80 \%$ weight criterion. For example, after 6 weeks of food intake averaging less than $60 \%$ of its ad-lib intake, Subject H7401 was reduced to only $87 \%$ of its free-feeding weight. Normative data provided by Zeigler, Green, and Siegel (1972) suggest that a challenge of $50 \%$ of freefeeding intake requires from 8 to 10 weeks to reduce the pigeon to an $80 \%$ weight criterion.

The efficiency with which each subject fed approximately doubled across the range of constraints stud ied, as shown in Figure 5. These measures illustrate that equal reinforcer durations do not ensure tha similar amounts of food will be obtained per oppor tunity. Instead, as in Experiment 1 (and as suggestec in Experiment 2), it appears that changes in the pi geon's feeding rate parallel changes in its responst 
Table 3

Summary Measures for Experiment 3

\begin{tabular}{|c|c|c|c|c|c|c|c|}
\hline \multirow{2}{*}{$\begin{array}{l}\text { FI Schedule } \\
\text { (in Minutes) }\end{array}$} & \multicolumn{2}{|c|}{$\begin{array}{l}\text { Access Time to Food } \\
\quad \text { (in Minutes) }\end{array}$} & \multicolumn{2}{|c|}{$\begin{array}{l}\text { Time Responding } \\
\text { (in Minutes) }\end{array}$} & \multirow{2}{*}{$\begin{array}{c}\text { Percentage } \\
\text { Weight }\end{array}$} & \multicolumn{2}{|c|}{$\begin{array}{l}\text { Food Intake } \\
\text { (in Grams) }\end{array}$} \\
\hline & Mean & $\mathrm{SE}$ & Mean & SE & & Mean & $\mathrm{SE}$ \\
\hline \multicolumn{8}{|c|}{ Subject H7401 } \\
\hline .25 & 27.2 & 1.3 & 74.5 & 3.4 & 102.5 & 21.4 & 1.1 \\
\hline .50 & 23.0 & 1.9 & 80.2 & 7.6 & 102.2 & 20.7 & .8 \\
\hline 1.00 & 17.9 & 1.2 & 85.7 & 8.1 & 100.0 & 18.7 & .9 \\
\hline 2.00 & 12.7 & .6 & 113.6 & 4.1 & 99.9 & 15.4 & .7 \\
\hline 4.00 & 10.7 & .2 & 165.5 & 10.9 & 95.6 & 13.7 & .7 \\
\hline 8.00 & 5.9 & .3 & 129.8 & 12.5 & 86.6 & 9.5 & .7 \\
\hline \multicolumn{8}{|c|}{ Subject $\mathrm{H} 7402$} \\
\hline .25 & 8.3 & .4 & 23.7 & 1.2 & 98.9 & 11.2 & .7 \\
\hline .50 & 8.4 & .5 & 25.0 & 2.4 & 95.9 & 13.0 & .6 \\
\hline 1.00 & 7.5 & .2 & 27.1 & .8 & 95.6 & 12.9 & .7 \\
\hline 2.00 & 5.6 & .2 & 19.8 & .6 & 96.4 & 10.2 & .5 \\
\hline 4.00 & 4.8 & .1 & 18.2 & .8 & 95.7 & 10.9 & .7 \\
\hline 8.00 & 4.9 & .1 & 43.7 & 6.4 & 93.7 & 9.7 & .4 \\
\hline \multicolumn{8}{|c|}{ Subject $\mathrm{H} 7403$} \\
\hline .25 & 22.6 & 2.0 & 58.7 & 5.4 & 100.6 & 19.6 & 1.2 \\
\hline .50 & 21.6 & 1.0 & 70.4 & 3.9 & 99.6 & 22.6 & .8 \\
\hline 1.00 & 18.7 & 1.0 & 79.8 & 3.0 & 99.4 & 21.1 & .9 \\
\hline 2.00 & 13.8 & .5 & 89.9 & 2.3 & 99.0 & 18.7 & .7 \\
\hline 4.00 & 10.9 & .4 & 159.1 & 17.7 & 96.3 & 18.3 & .6 \\
\hline 8.00 & 7.8 & .1 & 311.0 & 7.7 & 93.0 & 14.4 & .4 \\
\hline
\end{tabular}

Note-All data are means based on the last 5 days in each condition except percentage weight data, which are 3-day means.

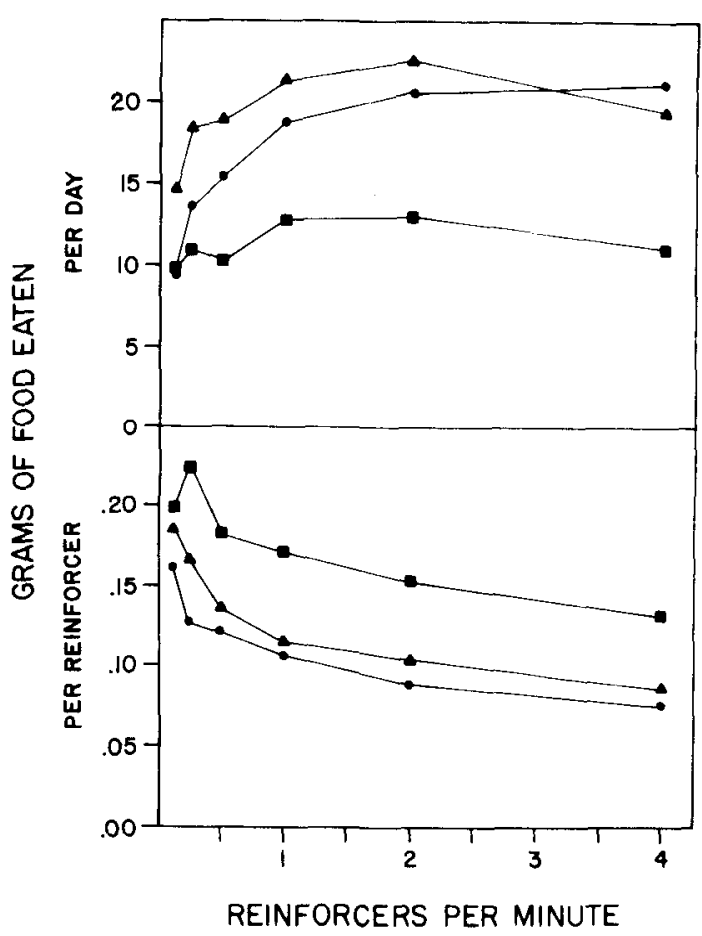

Figure 5. Mean weight of food intake per day (top) and per reinforcer (bottom) across the maximum scheduled frequency of reinforcement in Experiment 3. Individual subjects are identified by the circles (H7401), squares (H7402), and triangles (H7403). rate when total daily access to food is obtained on a reinforcement schedule. It would be interesting to determine whether similar effects occur in operant schedules under fixed-deprivation procedures. The photocell measures of head-into-hopper for Subject $\mathrm{H} 7403$ indicated that this subject responded to more than $98 \%$ of all reinforcer presentations. Observations of all three subjects support this estimate. From observations, it appeared that the increase in feeding efficiency resulted from a decrease in the occurrence of "nonessential" components of the feeding pattern in favor of higher rates of food-pecking alone. These "nonessential" components included most pausing or inspecting before initiating pecking, any sorting behaviors, and a reduction in momentary pauses between food pecks. These latter pauses typically include time spent handling (mandibulating) grain and swallowing (which frequently follows mandibulation). As a result, the pigeon frequently accumulated a number of pieces of grain in its beak before swallowing movements were apparent. Zeigler (1976) has previously reported this pattern in White Carneaux pigeons. Estimates of food-peck rates based on rate of intake suggest that, under the FI 8-min schedule, these subjects pecked at grain with rates in excess of $100 \mathrm{pecks} / \mathrm{min}$, approaching 140 pecks $/ \mathrm{min}$ for Subject $\mathrm{H} 7402$.

Also apparent in these data is an obvious source of 
individual difference. Throughout the present studies, most behavioral measures for Subject $\mathrm{H} 7402$ were below the same measures obtained from the other subjects. However, the same scheduled limits on reinforcer availability should have imposed substantially less constraint on food intake for this subject. Not only did this pigeon require less food to maintain its ad-lib body weight, but it also obtained more food within the same reinforcer duration.

The distribution of keypecking across hours of the day for each FI schedule is shown in Figure 6. Data are mean percentages averaged across subjects from response distributions for the last 5 days in each condition. Consistent with the previous studies, the response distribution followed a clear diurnal rhythm, with almost all responses occurring during the daylight hours. The morning peak of responding, seen prominently under the CRF schedules in Experiment 1 , was less apparent under the present schedules. As in Experiment 2, a greater proportion of responding occurred during the afternoon portion of the feeding pattern as constraints on food availability increased. Response distributions were significantly different from the combined CRF distribution for all FI schedules except for the FI .25-min schedule. The obtained values were $\chi^{2} s(11)=25.6,23.0,38.6,62.2$, and 25.7 for comparisons across daylight hours for the FI .5-, 1-, 2-, 4, and 8-min schedules, respectively (all ps $<.02$ ). For the FI .25-min schedule, $\chi^{2}(11)=$ 9.9, $\mathrm{p}>.50$. As in Experiment 2, the hour of peak responding appeared about $1 \mathrm{~h}$ later in the day compared with the CRF distribution as access to food was restricted.

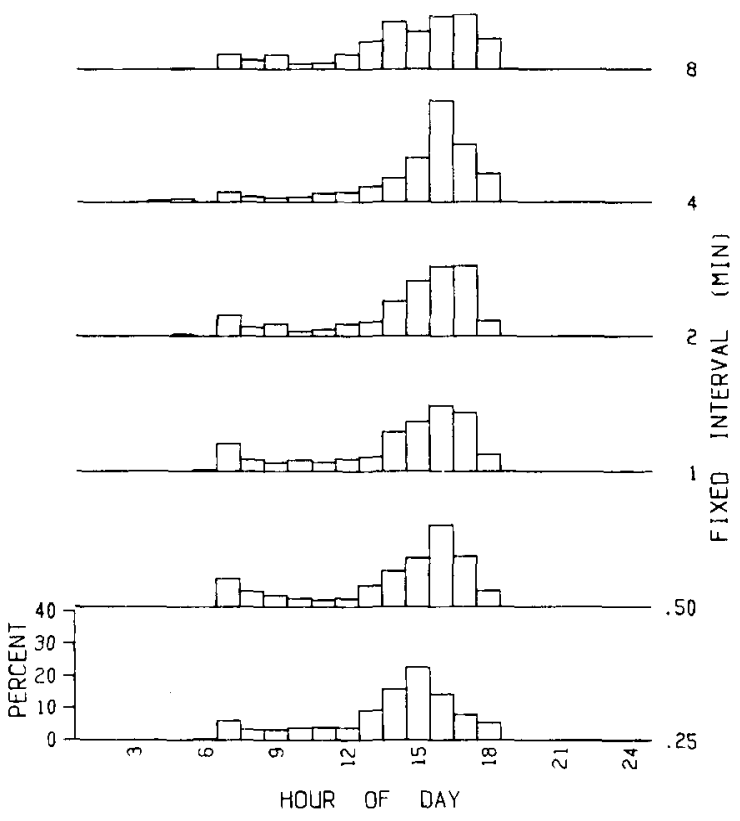

Figure 6. The mean percentage of daily responses distributed across hours of the day In Experiment 3. Light onset occurred after Hour $6(0600)$, light offset after Hour $18(1800)$.
Following completion of Experiment 3, the subjects were retested on some interval schedules while daily periods of free access to grain were also available. Subsequently, feeding cups were placed adjacent to the hopper aperture, the food hopper was disconnected, and baseline estimates were obtained for keypecking and food intake across a 1-week period. Since these baseline measures may be important to certain models of reinforcement, they are presented in Table 4. Relatively little keypecking occurred under baseline conditions. Food intake was comparable to those amounts obtained under the longer reinforcer durations in the CRF schedules shown in Table 1. Standard errors for all comparisons overlapped, except for comparisons at the $1.5 \mathrm{sec}$ duration.

\section{GENERAL DISCUSSION}

\section{Response to Constraint}

The current studies demonstrate an inverse relation between the pigeon's response rate and food availability. This inverse relationship is consistent with the results reported for a variety of species when total daily access to a given reinforcer was obtained under a schedule contingency (e.g., Allison, 1980; Allison, Miller, \& Wonzy, 1979; Collier et al., 1972; Collier et al., 1977; Duncan, Horne, Hughes, \& Woodgush, 1970; Hirsch \& Collier, 1974; Hursh, 1978; Kanarek, 1975). The results obtained here under FI schedules were remarkedly similar whether food was restricted by varying the duration of reinforcement or the time between reinforcers, and whether the rate of reinforcement increased or decreased. The changes in food availability produced large changes in responding even when deprivation, as measured by amount of intake or body weight, was small or inconsistent with the direction of change. In addition, the inverse relationship between keypeck rates and food availability was obtained both for the overall amount of responding per day and for local measures of response rate.

While some dependency between response rate and reinforcer availability may still remain under interval schedules (see Hursh, 1978), the present data clearly support both Allison (1980) and Hursh (1978) in showing that the inverse relation between instrumental rate and reinforcer availability does not require a ratio contingency between responding and reinforcer availability. Indeed, this inverse relationship appeared as robust under the present interval schedules as those previously reported under ratio schedules (e.g., Collier et al., 1977) despite the reduced dependency. The data also support Hursh's (1978) observation that the increase in instrumental rate can occur in the absence of any consistent change in body weight, lending support to the view that these behavioral changes antecede any physiological deficits (see Collier et al., 1972; Hirsch \& Collier, 1974). 
Table 4

Baseline Measures Obtained After Some Delay

Following Experiment 3

\begin{tabular}{|c|c|c|c|c|c|c|c|}
\hline \multirow{2}{*}{$\begin{array}{c}\text { Sub- } \\
\text { ject }\end{array}$} & \multicolumn{2}{|c|}{ Responses } & \multicolumn{2}{|c|}{$\begin{array}{c}\text { Time } \\
\text { Responding } \\
\text { (in Minutes) }\end{array}$} & \multirow{2}{*}{$\begin{array}{c}\text { Percentage } \\
\text { Weight }\end{array}$} & \multicolumn{2}{|c|}{$\begin{array}{l}\text { Food Intake } \\
\text { (in Grams) }\end{array}$} \\
\hline & Mean & $\mathrm{SE}$ & Mean & $\mathrm{SE}$ & & Mean & $\mathrm{SE}$ \\
\hline H7401 & 13.4 & 3.7 & 2.0 & .6 & 98.3 & 23.7 & 1.0 \\
\hline H7402 & 2.2 & .7 & .3 &.$I$ & 98.8 & 13.2 & .8 \\
\hline H7403 & 12.4 & 4.4 & 2.3 & .7 & 100.4 & 21.2 & 1.0 \\
\hline
\end{tabular}

Note-Data are 5-day means.

What, then, supports the inverse relationship between instrumental rate and reinforcer availability? The present results suggest that restrictions on food availability can motivate behavior, even if these restrictions do not reduce food intake. Timberlake and Allison (1974; see also Allison \& Timberlake, 1974, 1975) have shown that restrictions on the availability of a given behavior produce a condition of response deprivation, a condition that appears both necessary and sufficient for the behavior to serve as an effective reinforcer in a response contingency. The concept of response deprivation makes it possible to view nonconsumatory behaviors as commodities that, when deprived, can serve as reinforcers. Presumably, the behaviors comprising the feeding activity itself are such commodities. From this perspective, Hirsch and Collier (1974) have suggested that constraint on a subject's preferred pattern of intake is sufficient to motivate related instrumental behaviors.

In the present study, the pigeon's free-feeding pattern of behavior is the commodity being restricted. The presence of grain promotes a variety of behaviors in the pigeon, only some of which result in immediate ingestion. In addition to grasping and swallowing, inspecting and sorting were common nonintake behaviors (cf. Zeigler, 1976). Indeed, caretakers of free-feeding pigeons often complain that sorting, not swallowing, is the pigeon's dominant response to a fresh supply of grain. Under the longer reinforcement durations of the CRF schedules (Experiment 1 ), the pigeon clearly produced more access time to food than it "needed" if intake was the only determiner. Similarly, Collier et al. (1977) reported that rats produced more access periods to food on CRF schedules than were required for eating. Undoubtedly, all of this time was not spent attending to food. However, photocell measures and direct observations revealed that a substantial amount of the pigeon's time was spent in food-related activities.

As periods of food availability were restricted, the pigeon obtained less total access time to food. However, some food-directed behaviors were less resistant to constraint than were others. For example, preferential grain intake was observed only under CRF schedules, and then only at relatively long reinforcer durations. Similarly, the sorting behavior itself was rarely observed at shorter reinforcer durations. The economic term elasticity has been used to describe the rate of change in consumption of a commodity (here, performing a contingent behavior) with respect to changes in its price or availability (for discussions of the application of economic principles in behavioral analysis, see Allison, 1979; Hursh, 1980; Lea, 1978). In this case, sorting may be considered a relatively elastic behavior, changing readily in response to small changes in constraint. In contrast, food-pecking was relatively inelastic, changing only slightly across large changes in constraint. Of particular interest is the observation that different components of the feeding activity varied in elasticity, so that some components of the feeding pattern were constrained more than others by the limited availability of food. Such differences in elasticity help to describe how the pigeon compensates for restricted access. In addition, they point up possible sources of confusion in measuring the amount of constraint imposed by a given schedule.

\section{Local Patterns of Responding}

Despite changes in the frequency and duration of reinforcement, the pattern of responding in the present study was strongly linked to the pigeon's bimodal feeding pattern (Zeigler et al., 1971). This rhythm persisted across schedules, although, in many conditions, a more even distribution of instrumental responding would have produced a substantial increase in daily food intake. In the same way, the pigeon never learned to conserve effort by reducing the intensity of afternoon response periods. A relatively high ratio of responses per reinforcer was always obtained during the afternoon period, although the pigeon frequently obtained food at low response rates during the midday portion of the daily cycle.

The predominance of responding during the light phase of the light-dark cycle cannot be attributed simply to the pigeon's inability to obtain food during the dark condition. During one of the transition days for Subject $\mathrm{H} 7403$, the houselight failed and this subject received one 12-h "light" period without illumination. The resulting daily record showed no gross differences from those of preceding days, although the total amount of responding appeared somewhat reduced. More remarkable, however, was a distinct termination of the afternoon response pattern within $30 \mathrm{~min}$ of the scheduled offset time for the houselight. In addition, it was not usual for a pigeon to respond with one or two small bouts of activity during the last few hours of darkness before light onset each morning.

Although the pigeon's responding followed the bimodal pattern typical of free-feeding behavior, there 
was some suggestion that the response distribution changed somewhat across constraints. This effect was best seen in Experiment 3, in which the response distribution across longer FI schedules displayed a lower proportion of responding in the early morning period and a greater proportion in the late afternoon period as compared with the CRF distribution. The reasons for this change are not apparent. The effect is not predicted by the pattern-deprivation model, and does not appear to have been previously reported in the feeding literature. However, on the basis of the present observations, it appears to be a consistent finding under moderate schedule restrictions.

In addition to maintaining a diurnal feeding rhythm across constraints, the pigeon also increased its local response rate, as measured by an increase in responding within $15 \mathrm{sec}$ of a previous response. In the CRF schedules, similar measures revealed that the pigeon increased the number of reinforcers obtained per bout, and decreased the time between reinforcers within bouts, when the duration of reinforcement decreased. Zeigler et al. (1971) have reported that the pigeon's diurnal rhythm of feeding is achieved by varying both the frequency and the duration of feeding bouts across time of day. However, the pigeon reacts to food deprivation (i.e., a loss of body weight) by increasing bout duration rather than the number of bouts. In Experiment 1, the pigeon responded to feeding restrictions on duration of access, as it would to weight-loss deprivation, by increasing bout size rather than frequency. Such changes in performance are in the direction to be expected if the pigeon defended a distinct meal size, in terms of amount or duration of access, within each local period of intake. However, it should be noted that the pigeon generally undercompensated for the shorter reinforcer durations (cf. Allison, 1980).

The pigeon's tendency to distribute local response rates across a diurnal feeding pattern is not readily explainable by models emphasizing molar equilibrium states (e.g., Premack, 1965; Timberlake, 1980). The peak afternoon response rates clearly violate the law of least effort and appear incompatible with a simple matching interpretation (Herrnstein, 1970; Mazur, 1975). These data also seem inconsistent with a tendency to optimize response allocations (Staddon, 1979). The response pattern appears most consonant with the hypothesis that constraints on preferred patterns of access to food increase the underlying motivation for food-related behaviors (Hirsch \& Collier, 1974). This pattern-deprivation hypothesis follows from the more general response-deprivation condition defined with respect to the local pattern of contingent behavior (Allison \& Timberlake, 1975).

An additional prediction appears to follow from the pattern-deprivation hypothesis. Note that, under a constant contingency, the constraint imposed by the schedule on the contingent behavior will vary directly, across time, with the baseline pattern of contingent behavior. In this way, the schedules used in the present study, although held constant across the day, imposed more of a restriction on the pigeon's preferred feeding pattern during the afternoon periods when unconstrained feeding was typically more frequent. Consistent with the pattern-deprivation hypothesis, these periods also supported the most instrumental responding. It follows, from these arguments, that if the baseline pattern of the contingent behavior were changed, then the amount of constraint would change in a corresponding manner, producing a shift in the distribution of instrumental behavior. That is, if the baseline pattern of the contingent behavior changes, then the pattern of instrumental responding should reflect the contingent behavior's shift in baseline pattern.

The local response patterns found in Experiment 2 support this prediction. As noted above, the pigeon responds to restrictions on access to food primarily by increasing bout length (Zeigler et al., 1971). Across the restrictions on reinforcer duration in Experiment 2 , the time spent keypecking increased by a factor of 7 to 10 times that for keypecking under the longest reinforcer duration. However, an examination of individual records indicates that the frequency of response bouts remained relatively constant under these same conditions. Instead, instrumental performance was characterized by longer bouts of responding, a pattern consistent with the expected change in feeding pattern following restricted intake. This observation, together with the diurnal pattern of keypecking, suggests that the local distribution of keypecking may be best characterized as a pattern of responding that tracked local changes in the preferred pattern of feeding behavior.

Dunham (1977) has discussed some of the difficulties in defining momentary measures of response probability (see, also, Timberlake, 1980; Timberlake \& Allison, 1974). Instead, Dunham suggests measuring preferred "burst durations" and "interburst intervals." In practice, this optimal-duration model appears to be highly similar to the pattern-deprivation hypothesis proposed here. However, Dunham (1977) emphasizes that no molar change in contingent access is required by the optimal-duration model. The present data suggest that, required or not, molar changes in the contingent response frequency occur when constraints are applied to the local pattern of access (cf. Premack, 1965, pp. 172-173). Furthermore, the observation that different components of the feeding pattern varied in their elasticity in response to schedule restrictions underscores the difficulty in ensuring that no molar changes have occurred in the contingent behavior. Thus, the difference here may be more one of emphasis than substance. 
The description of local baseline patterns remains an empirical problem. In many cases, molar estimates of baseline responding may be adequate to predict the effects of a response contingency. However, local measures appear necessary to predict the patterns in instrumental performance produced by constraints applied at local levels on reinforcer availability. For the pigeon's bimodal feeding pattern, rates based on frequent (e.g., hourly) time samples appear to be adequate (cf. Terhune, 1978). However, measures within feeding bouts revealed that some responding changed within a time frame of $15 \mathrm{sec}$ or less. It seems unlikely that the pigeon would defend its diurnal pattern with such accuracy. But, once a feeding bout was initiated, the pigeon clearly appeared to defend some local measure of bout duration, as Dunham's (1977) model would predict. Presumably, these molecular patterns reflect the operation of underlying physiological mechanisms. In this regard, Zeigler's (1976) conclusion that oral stimuli play a tonic role in "motivating" the pigeon's feeding activity seems particularly relevant.

\section{REFERENCES}

Allison, J. Demand economics and experimental psychology. Behavioral Science, 1979, 24, 403-415.

Allison, J. Conservation, matching, and the variable-interval schedule. Animal Learning \& Behavior, 1980, 8, 185-192.

Allison, J., Miller, M., \& WozNY, M. Conservation in behavior. Journal of Experimental Psychology: General, 1979, 108, 4-34.

Allison, J., \& Timberlake, W. Instrumental and contingent saccharin-licking in rats: Response deprivation and reinforcement. Learning and Motivation, 1974, 5, 231-247.

Allison, J., \& Timberlake, W. Response deprivation and instrumental performance in the controlled-amount paradigm. Learning and Motivation, 1975, 6, 122-142.

Collier, G., Hirsch, E., \& Hamlin, P. The ecological determinants of reinforcement in the rat. Physiology \& Behavior, $1972,9,705-716$.

Collier, G., Hirsch, E., \& Kanarek, R. The operant revisited. In W. K. Honig \& J. E. R. Staddon (Eds.), Handbook of operant behavior. Englewood Cliffs, N.J: Prentice-Hall, 1977.

Duncan, I. J. W., Horne, A. R., Hughes, B. O., \& WoodGush, D. G. M. The pattern of food intake in female brown leghorn fowls as recorded in a Skinner box. Animal Behaviour, $1970,18,245-255$.

Dunham, P. The nature of reinforcing stimuli. In W. K. Honig \& J. E. R. Staddon (Eds.), Handbook of operant behavior. Englewood Cliffs, N.J: Prentice-Hall, 1977.

Herrnstein, R. On the law of effect. Journal of the Experimental Analysis of Behavior, 1970, 8, 399-412.

Hirsch, E., \& Collier, G. The ecological determinants of reinforcement in the guinea pig. Physiology \& Behavior, 1974, 12, 239-249.

Hursh, S. R. The economics of daily consumption controlling food- and water-reinforced responding. Journal of the Experimental Analysis of Behavior, 1978, 29, 475-491.

HuRst, S. R. Economic concepts for the analysis of behavior. Journal of the Experimental Analysis of Behavior, 1980, 34, 219-238.

KanareK, R. B. Availability and caloric density of the diet as determinants of meal patterns in cats. Physiology \& Behavior, $1975,15,611-618$.
LEA, S. E. G. Psychology and economics of demand. Psychological Bulletin, 1978, 85, $441-446$.

Mazur, J. E. The matching law and quantifications related to Premack's principle. Journal of Experimental Psychology: Animal Behavior Processes, 1975, 1, 374-386.

McFarland, D. J. Phase relationships between feeding and drinking in the Barbary dove. Journal of Comparative and Physiological Psychology, 1967, 63, 208-213.

Murton, R. K. The wood pigeon. London: Collins, 1965.

Premack, D. Reinforcement theory. In D. Levine (Ed.), Nebraska Symposium on Motivation (Vol. 13). Lincoln: University of Nebraska Press, 1965.

Schmid, W. D. Energy intake of the mourning dove Zenaidura macroura marginella. Science, 1965, 150, 1171-1172.

Staddon, J. E. R. Operant behavior as adaptation to constraint. Journal of Experimental Psychology: General, 1979, 108, 48-67.

Terhune, J. G. The relationship between momentary response probabilities and momentary reinforcement effects. Animal Learning \& Behavior, 1978, 6, 187-192.

Timberlake, $W$. The application of the matching law to simple ratio schedules. Journal of the Experimental Analysis of Behavior, 1977, 27, 215-217.

Timberlake, W. A molar equilibrium theory of learned performance. In G. H. Bower (Ed.), Psychology of learning and motivation (Vol. 14). New York: Academic Press, 1980.

Timberlake, W., \& Allison, J. Response deprivation: An empirical approach to instrumental performance. Psychological Review, 1974, 81, 146-164.

Van Hemel, S. B., \& Meyer, J. S. Feeding patterns and responses to caloric dilution in the Japanese quail. Physiology \& Behavior, 1969, 4, 339-344.

ZEIGLER, H. P. Feeding behavior of the pigeon. In J. S. Rosenblatt, R. A. Hinde, E. Shaw, \& C. Beer (Eds.), Advances in the study of behavior (Vol. 7). New York: Academic Press, 1976.

ZEigler, H. P., \& Feldstein, R. A feedometer for the pigeon. Journal of the Experimental Analysis of Behavior, 1971, 16, 181-187.

Zetgler, H. P., Green, H. L., \& Lehren, R. Patterns of feeding behavior in the pigeon. Journal of Comparative and Physiological Psychology, 1971, 76, 468-477.

Zeigler, H. P., Green, H. L., \& Siegel, J. Food and water intake and weight regulation in the pigeon. Physiology \& Behavior, 1972, 8, 127-134.

Zeigler, H. P., Miller, M., \& Levine, R. R. Trigeminal nerve and eating in the pigeon (Columba livia): Neurosensory control of the consummatory response. Journal of Comparative and Physiological Psychology, 1975, 89, 845-858.

\section{NOTES}

1. Proponents of response deprivation generally do not invoke motivation as an intervening variable (e.g., Timberlake \& Allison, 1974). However, it is clear that the response-deprivation condition describes a state of the organism in which a change in behavior is predicted. This is the sense in which the term is used here.

2. I am indebted to Bill Timberlake for suggesting this term.

3. None of the subjects had had any experience on fixeddeprivation schedules. Feeder and keypeck training were previously accomplished without specific deprivation by removing available food sources and initiating an autoshaping procedure (Brown \& Jenkins, 1968). The shaping procedure used a 30-sec keylight CS, a 6-sec grain delivery, and a fixed 600 -sec intertrial interval. Two of the three subjects acquired keypecking in the "afternoon" of the first day, the third subject on the "morning" of the following day.

4. With a mean weight of $.02 \mathrm{~g}$ per piece of grain, the "grams per minute" measure converts directly to "pecks per second," assuming a peck-to-consumption ratio of 1.2. The mean peck-to- 
consumption ratio for other pigeons with freestanding food was about $1.4 \pm .2$ pecks per grain, based on observations with the same grain mixture. Normative data for the White Carneaux pigeon using another grain mixture supports this estimate (Zeigler, Miller, \& Levine, 1975).

5. Zeigler (1976) reports that more than $90 \%$ of all feeding responses in the pigeon occur at rates above .60 pecks/sec. Based on the type of feedometer used (Zeigler \& Feldstein, 1971), these rates would not appear to include most time spent inspecting food, since the operation of the photocell required a beak position close to contacting (within .5 in. of) the grain. This measure did include sorting, although Zeigler and Feldstein took precautions to minimize sorting.

(Manuscript received December 12, 1980; revision accepted for publication May 1, 1981.) 